\title{
ON TWO NEW MEDUSAE, MERGA REESI N.SP. AND TIAROPSIDIUM ATLANTICUM N.SP.
}

\author{
By F. S. Russell, F.R.S. \\ The Plymouth Laboratory
}

(Text-figs. I-3)

In a collection made with a $2 \mathrm{~m}$ stramin ring trawl at $47^{\circ} \mathrm{I2} 2^{\prime} \mathrm{N}$., $7^{\circ} 4 \mathrm{O}^{\prime} \mathrm{W}$. on 2I July I955, with 450 fathoms of wire out, I have found two new species of medusae. These were each represented by a single specimen, one of which was an anthomedusa and the other a leptomedusa.

The anthomedusa was much crushed and contracted, but it was nevertheless intact and it has been possible to make a fairly complete description of it. It is apparently a pandeid, but I have had difficulty in placing it in a known genus. It is evident that the classification of some pandeids needs revision, but until more is known it seems premature to attempt this. In the meanwhile I am provisionally placing this new species in the genus Merga, as Kramp (1956) has recently done for another new pandeid. I propose to call it $M$. reesi n.sp. after my colleague Dr W. J. Rees, whose researches on hydroids and their medusae are well known.

The medusa, of which a reconstruction is given in Fig. I, can be described as follows.

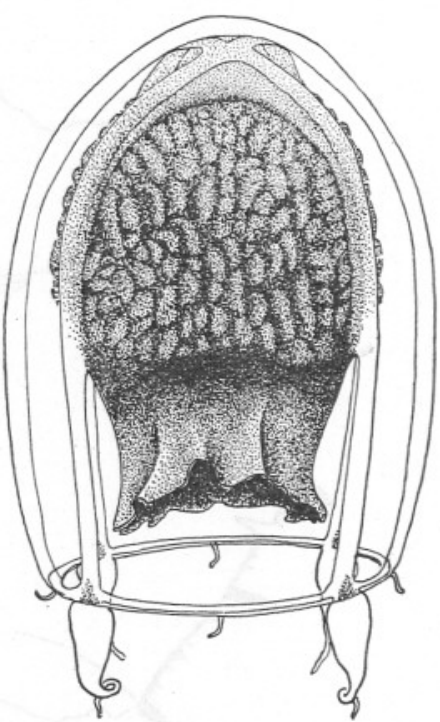

Fig. I. Merga reesi n.sp. Reconstruction from damaged specimen.

\section{Merga reesi n.sp.}

Umbrella bell-shaped, higher than wide, no apical process. Stomach flaskshaped, not extending beyond umbrella margin, with broad base. Mouth with four slightly crenulated lips. Four radial canals and ring canal broad, with smooth outlines. Radial canals attached to stomach over more than half its length to form 'mesenteries'. Gonads interradial, irregularly folded to form numerous small raised corrugations. Four perradial marginal tentacles with 
swollen elongated basal bulbs, without exumbrellar spurs. Four small tentaculae, one in each interradius. No ocelli. Height ro $\mathrm{mm}$. Colour of stomach and gonads dark chocolate red; basal bulbs of marginal tentacles colourless, except for slight internal pigmentation at junction of radial canal and ring canal.

The specimen has been deposited in the British Museum (Natural History) and has been given the registered number B.M. 1956.4.I4.I.

The other specimen was a large leptomedusa. I showed it to Dr P. L. Kramp, when he was in Plymouth, and he immediately identified it as a species of the mitrocomid genus Tiaropsidium. The medusa has the distinctive characters typical of that genus.

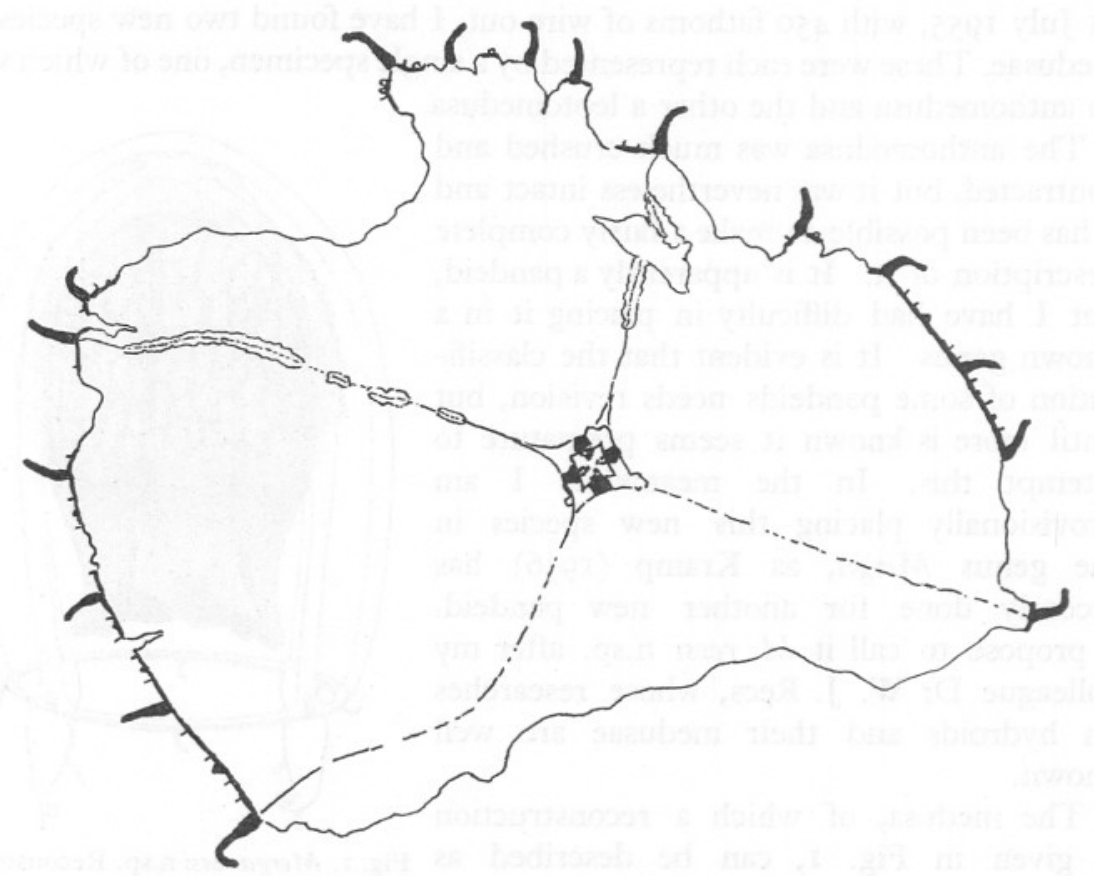

Fig. 2. Tiaropsidium atlanticum n.sp. Drawing of specimen showing actual state of preservation.

The specimen is somewhat damaged; the margin of the umbrella is not entire and some of the gonads are missing. Nevertheless, the portions that remain are in a good state of preservation. The umbrella is about $60 \mathrm{~mm}$ in diameter and flatter than a hemisphere. The most striking feature is the black pigment on the stomach and on the large marginal tentacles.

The medusa most closely resembles $T$. japonicum Kramp. It differs from 
that species in its greater size, its higher number of marginal tentacles and vesicles, and the presence of the black pigment.

In outline the stomach resembles exactly the drawing given by Kramp (I932, text-fig. I) for that of T. japonicum, but on each of its interradial walls it has black areas forming four triangles on the base of the stomach each of which is continued as a black streak down each mouth lip (Fig. $3 a, b$ ). The gonads are linear and extend along the middle three-quarters of the radial canals; they have median longitudinal divisions. The specimen is a mature male and the gonads are somewhat follicular in appearance (Fig. $3 d$ ).

The large marginal tentacles appear to be similar in form to those of T. japonicum. Each tentacle has a narrow abaxial and a broader adaxial streak clearly demarcated from the black pigmented lateral areas; these may be indications of a similar arrangement of muscles to that described by Kramp (1932, p. 328) for T. japonicum. There is a triangular prolongation of the exumbrella extending a short way down the abaxial side of the base of each tentacle (Fig. $3 c, d$ ).

The medusa has the small tentacles on the umbrella margin characteristic of the genus, and the open marginal vesicles are typical, each having a large black ocellus and containing I 2 to 20 , or possibly more, concretions.

A drawing of the whole medusa, showing the missing portions of the umbrella margin, is given in Fig. 2. I have counted the marginal organs in those parts of the margin which are complete and the sequence in each quadrant is as follows:

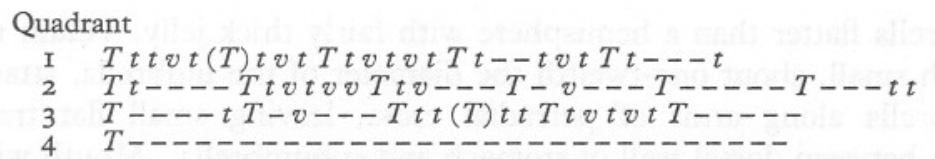

$T=$ large marginal tentacle; $(T)=$ bulb of developing large tentacle; $t=$ small marginal tentacle; $v=$ marginal vesicle. The dashes indicate missing portions. The first $T$ in each quadrant is opposite a radial canal.

It is to be seen that the greatest number of large tentacles in any one quadrant is six, the number in the remaining two complete quadrants being 4 plus I developing and 5 plus I developing, respectively. A drawing of the first two sections of the first quadrant is given in Fig. 3 c. In the centre of the first section between two large tentacles (on the left) there is a bulb of a developing large tentacle; this is flanked on either side by two small tentacles with a marginal vesicle between them, and on one side a third small tentacle developing. In the second section (on the right) there are two marginal vesicles each flanked on the outer side by a small tentacle and having a third small tentacle between them. There are evident abnormalities such as two marginal vesicles adjoining one another in the second section of the second quadrant, and no marginal vesicles in the third section of the third quadrant.

It seems reasonable to suppose that the sequences in the second sector of the first quadrant and the fourth sector of the third quadrant represent the final 
development, that is two marginal vesicles and three small tentacles between two large tentacles. On this basis a fully developed specimen could have

$$
\begin{aligned}
4 \times 6 & =24 \text { large tentacles } \\
24 \times 3 & =72 \text { small tentacles } \\
24 \times 2 & =48 \text { marginal vesicles }
\end{aligned}
$$

In my damaged specimen there are three quadrants complete as regards the large marginal tentacles. The number of large tentacles in these three quadrants was 15 plus 2 developing. If the specimen had been complete it is therefore likely that it would have had at least twenty fully developed large tentacles.

This medusa therefore differs from all known species of the genus Tiaropsidium in having a considerably higher number of large marginal tentacles and marginal vesicles, the greatest number so far being 8 tentacles and 16 marginal vesicles, in T. japonicum. The combination of higher numerical characters, striking black pigment, and locality of capture supplies sufficient grounds for regarding this specimen as belonging to a new species to which I give the name $T$. atlanticum.

Since this new species may perhaps have as many as 48 marginal vesicles it will be necessary to amend the generic diagnosis given by Kramp (I932, p. 366) accordingly.

The new species may be described as follows:

\section{Tiaropsidium atlanticum n.sp.}

Umbrella flatter than a hemisphere with fairly thick jelly. Velum narrow. Stomach small, about one-twelfth the diameter of the umbrella, attached to subumbrella along arms of perradial cross, leaving small flat triangular pouches between dorsal wall of stomach and subumbrella. Mouth with four short broad lips with slightly folded margins. Four straight radial canals and ring canal narrow. Gonads along four radial canals, linear, with median division; along middle three-quarters of radial canal, not reaching to umbrella margin. Large marginal tentacles hollow, probably up to 24 in number, with elongated swollen bases. Small marginal tentacles solid, probably up to 72 in number, three in each space between two large marginal tentacles. Probably up to 48 open marginal vesicles, two in each space between two large marginal tentacles, each with c. I2 to 20 , or more, concretions and one black ocellus at base. Diameter c. $60 \mathrm{~mm}$. Colour on interradial walls of stomach and large marginal tentacles black.

The specimen has been deposited in the British Museum (Natural History) and has been given the registered number B.M. I956.4.I4.2.

My thanks are due to Captain C. A. Hoodless and the crew of R.V. Sarsia who collected these specimens; and to Dr P. L. Kramp for reading through the manuscript. 

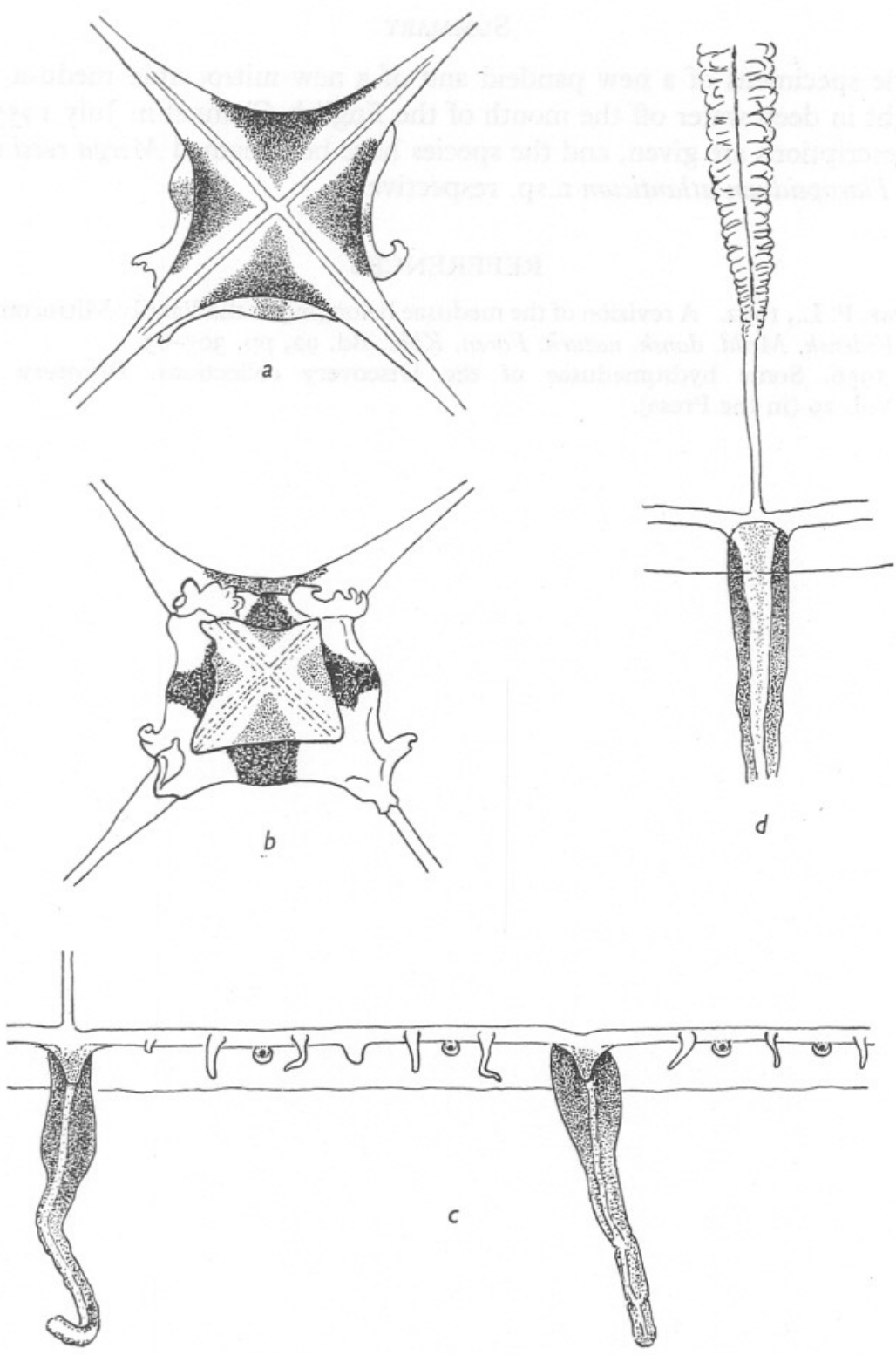

Fig. 3. Tiaropsidium atlanticum n.sp. Outline drawings in which dotted areas indicate black pigmentation: $a$, Dorsal view of stomach; $b$, ventral view of stomach; $c$, portion of umbrella margin seen from abaxial side showing two large tentacles, one bulb of large tentacle developing, small tentacles and marginal vesicles; $d$, adaxial view of large tentacle and portion of gonad. 


\section{SUMMARY}

Single specimens of a new pandeid and of a new mitrocomid medusa were caught in deep water off the mouth of the English Channel in July 1955.

Descriptions are given, and the species have been named Merga reesi n.sp. and Tiaropsidium atlanticum n.sp. respectively.

\section{REFERENCES}

KRAMP, P. L., I932. A revision of the medusae belonging to the Family Mitrocomidae. Vidensk. Medd. dansk. naturh. Foren. Kbh., Bd. 92, pp. 305-83.

- 1956. Some hydromedusae of the Discovery collections. Discovery Rep., Vol. 29 (in the Press). 